\title{
Effects of Ultrasound on the Degradation of
}

\section{Pentachlorophenol by Boron-Doped Diamond Electrodes}

\author{
Gustavo S. Garbellini, ${ }^{1, *}$ Giancarlo R. Salazar-Banda, ${ }^{2}$ Luis A. Avaca ${ }^{1}$ \\ ${ }^{1}$ São Paulo University, Institute of Chemistry of São Carlos, CP 780, 13560-970 São Carlos - SP, Brazil \\ ${ }^{2}$ Tiradentes University / Institute of Technology and Research, 49032-490 Aracaju - SE, Brazil
}

Received 15 July 2010; accepted 9 November 2010

\begin{abstract}
The beneficial effects of the ultrasound (US) like the cleaning of electrode surface and enhancement of mass transport were evaluated in association with potentiostatic electrolyses for the degradation of pentachlorophenol (PCP) at $3.0 \mathrm{~V} v s$. $\mathrm{Ag} / \mathrm{AgCl}$, using a boron-doped diamond (BDD) electrode during 270 minutes. Different decay levels of the PCP spectrum bands in 220, 251 and $321 \mathrm{~nm}$, respectively, were observed after application of ultrasound without electrochemical process (18.1, 17.7 and $19.8 \%$ ), silent electrolyses (29.3, 71.6 and $70.8 \%$ ), pulsed sonoelectrolysis (31.0, 75.1 and $76.3 \%$ ) and sonoelectrolyses (39.2, 80.0 and 82.6\%). For silent and sonoelectrolyses processes, cleaning/reactivation of the BDD surface by acetonitrile and/or electrochemical treatment was necessary. The pulsed sonolectrolysis were carried out purposely without cleaning/reactivation of the surface. The results showed greater PCP degradation for insonated studies than those obtained for the silent electrolyses, due to the increase of mass transport, minimization of the electrode fouling and the combined generation of hydroxyl radicals by both ultrasound and the polarized BDD surface. These tools (US and BDD), especially the pulsed sonoelectrolysis, can improve the degradation of pesticides and their metabolites in the environment and enable the use of sonoelectrochemistry for wastewater remediation.
\end{abstract}

Keywords: ultrasound, diamond electrode, degradation, pesticides, sonoelectrolysis.

\section{Introduction}

The determination and degradation of toxic organic compounds in the environment using electrochemical methods have been extensively performed on different electrode materials [1-4]. However, this kind of studies is strongly

\footnotetext{
* Corresponding author. E-mail address: gustgarb@yahoo.com.br
} 
prejudiced by adsorption and/or insolubilization of the oxidation and/or reduction products on the electrode surfaces, yielding the irreproducibility of the electroanalytical measurements and a loss in the degradation process efficiency.

Whereupon it, the ultrasound radiation has been associated to electrochemical measurements because this promotes a significant increase of the transport of electroactive species and an efficient cleaning of the electrode surface [5-8]. These beneficial effects improve the analytical sensitivity as compared to silent measurements and promote the continuous activation of the electrode surface, facilitating the analysis of the organic compounds in complex samples. These effects can also improve the process of the electrochemical degradation of species in solution. Many works have been published in the literature involving the sonoelectroanalytical determination and sonoelectrochemical degradation of organic compounds, especially using the boron-doped diamond (BDD) electrode [9-13].

BDD materials have not presented features of erosion or destruction of their surface on extreme electrochemical conditions as a result of their mechanical robustness, characterizing this material as ideal for sonoelectrochemical experiments [14]. Furthermore, the simultaneous generation of hydroxyl radicals by both the ultrasound due to the water sonolysis [15] and the BDD surface at high potential values (water electrolysis) can contribute for a more efficient degradation of organic compounds, being an interesting alternative for their complete mineralization.

Chlorophenols constitute a particular group of toxic organic compounds that present carcinogenic effects in humans. Particularly, pentachlorophenol (PCP) is applied as fungicide, insecticide and wood preservation. There are many risks of contamination of the groundwater with consequent contamination of drinking water, due to its solubility and persistence in water $[16,17]$. In a study performed by Codognoto et al. [18], the authors carried out the electrochemical degradation of PCP using the BDD electrode, evaluating the effect of the applied potential to the working electrode. In all cases, an intense inactivation of the electrode surface, as a result of adsorption and/or insolubilization of the oxidation products and pesticide, was observed. Therefore, constant cleaning and reactivations of the BDD surface were necessary.

Therefore, the aim of this study is to evaluate the beneficial effects of ultrasound radiation, mainly the minimization of the electrode fouling on the sonoelectrochemical degradation of PCP by potentiostatic electrolyses.

\section{Experimental}

\section{Reagents and solutions}

Stock solutions $1.0 \times 10^{-2} \mathrm{~mol} \mathrm{~L}^{-1}$ of the pesticide PCP (Aldrich, 98.0\%) in pure acetonitrile were prepared. For the study of PCP, a Britton-Robinson (BR) 0.1 mol L $\mathrm{L}^{-1}$ buffer solution prepared with analytical grade reagents and optimized at $\mathrm{pH}=5.5$ with small quantities of $1 \mathrm{~mol} \mathrm{~L}^{-1} \mathrm{NaOH}[18,19]$ was always used as supporting electrolyte. 


\section{Instrumentation}

The electrolyses were carried out using a PGSTAT 30 Autolab (Eco Chimie B.V., Netherlands). The ultrasound radiation was delivered into the cell via a VCX 130 model ultrasonic horn (Sonics \& Materials, USA), able to transmit radiation at a fixed frequency of $20 \mathrm{kHz}$ in a maximum power of $14 \mathrm{~W}$. The observation of the PCP concentration decrease was performed by means of spectra obtained on the ultraviolet region [20] using a HITACHI U-2010 spectrophotometer with quartz cells of optical length of $1 \mathrm{~cm}$.

The boron-doped diamond films used in this study (Adamant Technologies SA, La Chaux-de-Fonds, Switzerland) have boron content of the order of $8000 \mathrm{ppm}$. The working electrode (BDD) had an exposed geometrical area of $0.42 \mathrm{~cm}^{2}$. The reference system was an $\mathrm{Ag} / \mathrm{AgCl}\left(3.0 \mathrm{~mol} \mathrm{~L}{ }^{-1} \mathrm{KCl}\right)$ electrode and the counter one was a $2 \mathrm{~cm}^{2} \mathrm{Pt}$ foil. The ultrasound horn tip was placed in front of the working electrode face. The electrochemical studies were carried out using a three-electrode arrangement fitted into a two-compartment Pyrex ${ }^{\circledR}$ glass cell (90 and $50 \mathrm{~mL}$ ) separated by a porous membrane that has an entrance for the ultrasound tip and degassing facilities for bubbling $\mathrm{N}_{2}$ (Fig. 1).

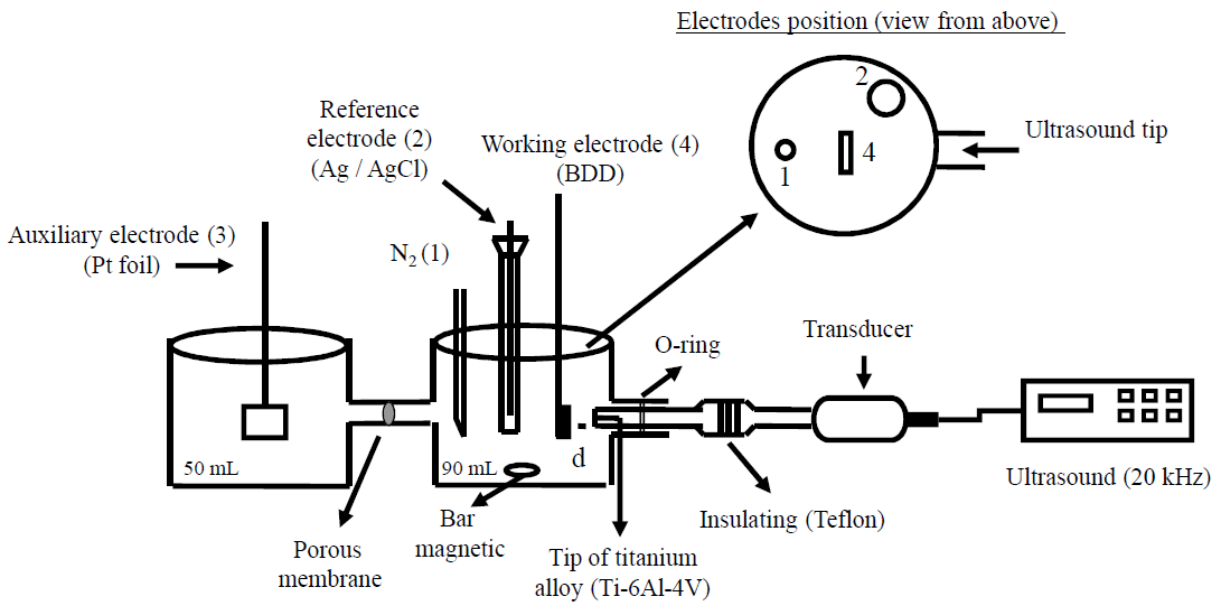

Figure 1. Electrochemical cell for the study of potentiostatic electrolyses in the absence and presence of ultrasound. The ultrasound tip was placed in front of the BDD electrode at a fixed distance (d) of $7 \mathrm{~mm}$.

In the first compartment cell $(90 \mathrm{~mL})$ the ultrasound tip, the BDD and reference electrodes, and the tube to bubble nitrogen were inserted. In the other compartment $(50 \mathrm{~mL})$ the auxiliary electrode was placed. The ultrasound tip was placed in front of the BDD electrode at a fixed distance $(d)$ of $7 \mathrm{~mm}$. The minimum $d(7 \mathrm{~mm})$ is imposed by the geometric configuration of the proposal sonoeletrochemical cell and it is, therefore, used for all electrolysis. A rubber Oring was placed between the tip of the ultrasound and the Teflon ${ }^{\circledR}$ made adapter connected to the cell to prevent possible water leakage. The intensity of applied ultrasound power was controlled by the tip vibration amplitude $(A)$ when placed inside the solution. The $A=20 \%$ (this parameter is selected in the proper equipment) was used because a higher value of this parameter heats the solution and causes some turbulence within the solution. The need of bipotentiostatic 
control of the titanium horn tip was overcome by insulating the transducer from the probe with a Teflon ${ }^{\circledR} \operatorname{disk}[5]$.

\section{Potentiostatic electrolyses}

Prior the experiments of controlled potential electrolyses, in the absence and presence of ultrasound, the BDD electrode received a pre-treatment in a $\mathrm{H}_{2} \mathrm{SO}_{4}$ $\left(0.5 \mathrm{~mol} \mathrm{~L}^{-1}\right)$ solution consisting of polarizations at +3.0 and $-3.0 \mathrm{~V}$ during 5 and $30 \mathrm{~s}$, respectively, to ensure reliable and reproducible electrochemical results [21] without producing degradation of the electrode surface [22].

The electrolyses were performed under agitation by a bar and magnetic stirrer at a concentration of $5.0 \times 10^{-5} \mathrm{~mol} \mathrm{~L}^{-1} \mathrm{PCP}$ in aqueous media (BR buffer $0.1 \mathrm{~mol}$ $\mathrm{L}^{-1}, \mathrm{pH} 5.5$ ) and using ultrasound fixed conditions of $d 7 \mathrm{~mm}$ and $A$ of $20 \%$. The degradation percentages calculated according to the decrease of the pesticide concentrations were determined by interpolation of the absorbance values obtained for the solutions before and after the degradation process in the analytical curve of the PCP standard.

Studies using ultrasound, silent electrolyses, pulsed sonoelectrolysis and sonoelectrolyses in a total time of 270 minutes were conducted and compared according to the percentage of analyte degradation, in order to evaluate the PCP degradation at $3.0 \mathrm{~V}$. The decrease of the PCP concentration was observed as follows: an optical spectrum UV of the solution containing the analyte subjected to degradation was obtained every 30 minutes (i.e. the experiment was interrupted), except for the case of pulsed sonoelectrolysis, whose spectra were obtained only before and after the degradation process.

Inactivation of the electrode surface was observed after 60, 150 and 210 min of electrolyses in the absence of radiation. The inactivation of the surface for the case of sonoelectrolyses occurred after each 30 minutes. Therefore, two procedures of surface cleaning/reactivations were tested. The first one consisted of surface cleaning with $2 \mathrm{~mL}$ of acetonitrile and the second one (electrochemical treatment) refers to the application of $+3.0 \mathrm{~V}$ and $-3.0 \mathrm{~V}$ for 5 and $30 \mathrm{~s}$, respectively, in $\mathrm{H}_{2} \mathrm{SO}_{4}\left(0.5 \mathrm{~mol} \mathrm{~L}^{-1}\right)$ solution.

For silent electrolyses, the cleaning of the surface with acetonitrile was not enough for the removal of the adsorbed species from the BDD surface. Thus, an electrochemical treatment was necessary for the reactivation of the diamond electrode after 60, 150 and $210 \mathrm{~min}$ of process. For the sonoelectrolyses, the cleaning of the surface with acetonitrile every 30 minutes was adequate for the removal of the adsorbed species. Therefore, the electrochemical treatment was not required. The pulsed sonoelectrolysis involved a combination of electrolysis in the presence $(30 \mathrm{~min})$ and absence $(5 \mathrm{~min})$ of ultrasound. This process was carried out purposely without cleaning/reactivation of the diamond electrode surface.

\section{Results and discussion}

Analytical curves for PCP by UV-Vis spectroscopy

Analytical curves in a concentration range from $4.94 \times 10^{-7}$ to $8.65 \times 10^{-5} \mathrm{~mol} \mathrm{~L}^{-1}$ of PCP were obtained by $\mathrm{UV}-\mathrm{V}$ is spectroscopy aiming to monitor the diminution 
of the PCP concentration through the degradation experiments. Fig. 2 presents UV spectra and the analytical curves.

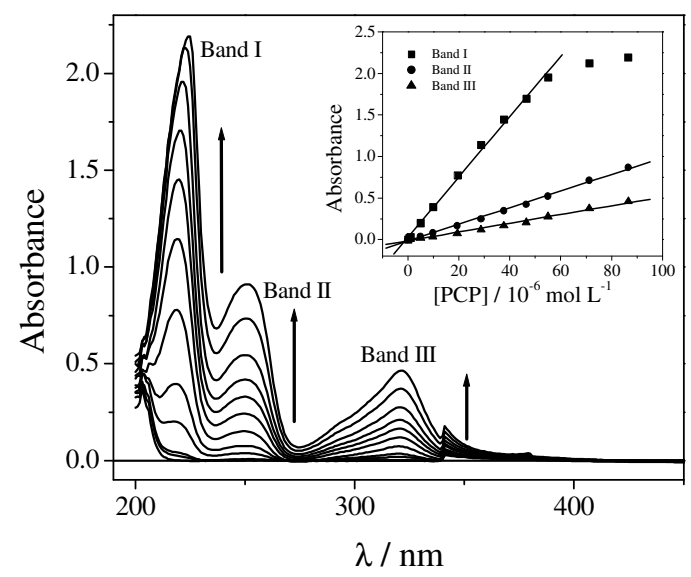

Figure 2. UV spectra for the PCP in a concentration range of $4.94 \times 10^{-7}$ to $8.65 \times 10^{-5}$ mol L ${ }^{-1}$ in aqueous solution (BR buffer $0.1 \mathrm{~mol} \mathrm{~L}^{-1}$ at $\mathrm{pH} 5.5$ ). The arrows for bands I, II and III indicate the increase of absorbance with increasing concentration of PCP analyzed. Inset: Analytical curves for each absorption band of PCP.

Three absorption bands with different intensities were noted in the spectrum of the PCP. A calibration curve and corresponding linear regression were performed for each band. The linear regression equations for the curves were: band I in 220 $\mathrm{nm}: \mathrm{A}=0.03634[\mathrm{PCP}]+0.02752$; band II in $251 \mathrm{~nm}: \mathrm{A}=0.00998[\mathrm{PCP}]-$ 0.01533 and band III in $321 \mathrm{~nm}: \mathrm{A}=0.00526$ [PCP] - 0.01486. Furthermore, it was observed that band I does not obey Beer's law over the entire range of concentration, and that bands II and III show good linearity (correlation coefficient, $r=0.9984$ and 0.9951 , respectively).

The UV spectrum of the PCP resembles to the characteristic of benzene, which presents three absorption bands, in 184 and $204 \mathrm{~nm}$ (both ethylene) and $256 \mathrm{~nm}$ (benzenoid), all originated from $\pi-\pi^{*}$ transitions [23]. For the PCP, the spectrum presented bands are shifted to higher wavelength due to strong substitution of the benzene ring, as well as by the influence of the aqueous media (0.1 mol L ${ }^{-1}$ BR buffer) [24]. After the spectroscopic characterization of the PCP response, the electrolyses were performed in the absence and presence of ultrasound.

\section{Potentiostatic electrolyses}

The oxidation of the PCP on the BDD electrode to define the potential value to be used in the electrolysis was evaluated by square wave voltammetry in BR buffer $0.1 \mathrm{~mol} \mathrm{~L}^{-1}(\mathrm{pH}=5.5)$ with pulse potential frequency of $100 \mathrm{~Hz}$, pulse amplitude of $50 \mathrm{mV}$ and scan increment of $2 \mathrm{mV}[18,19]$. This pesticide showed a single peak (Fig. 3), which is characteristic of an irreversible process (no reverse current), at a potential of $0.74 \quad \mathrm{~V}$ vs. $\mathrm{Ag} / \mathrm{AgCl}$ having tetrachlorobenzoquinone as voltammetric oxidation product. 


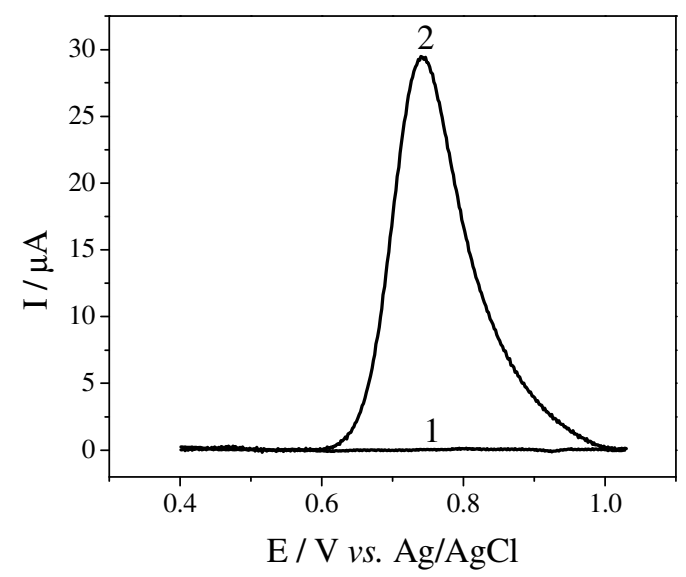

Figure 3. Square wave voltammograms for BR buffer $0.1 \mathrm{~mol} \mathrm{~L}^{-1} \mathrm{pH}=5.5$ (1) and for the oxidation of $5.0 \times 10^{-5} \mathrm{~mol} \mathrm{~L}^{-1} \mathrm{PCP}(2)$ on BDD electrode. Conditions: BR buffer $0.1 \mathrm{~mol} \mathrm{~L}^{-1}(\mathrm{pH}=5.5)$ as supporting electrolyte with $\mathrm{f}=100 \mathrm{~Hz}, \mathrm{a}=50 \mathrm{mV}, \Delta \mathrm{Es}=2$ $\mathrm{mV}$.

It is known that BDD electrodes can electrogenerate hydroxyl radicals at high potential values, e.g. 3.0 V [25], in the potential region of oxygen evolution (water decomposition). Therefore, the ultrasound was applied together with the potentiostatic electrolyses at $3.0 \mathrm{~V}$ vs. $\mathrm{Ag} / \mathrm{AgCl}$ to minimize the blocking of the electrode surface and possibly obtain higher levels of degradation of the pesticide, since there is the sum of hydroxyl radicals amount generated by both BDD (at the interface electrode solution) and ultrasound within the solution (water sonolysis).

Comparison of electrolyses of the PCP at $3.0 \mathrm{~V}$ in the absence and presence of ultrasound on the BDD electrode showed an increase in mass transport promoted by ultrasound, since sonoelectrolyses (curve 2) showed current intensities 1.5 times higher than that obtained by silent electrolyses (curve 1), as shown in Fig. 4. In both electrolyses, there was no decay of current due to the occurrence of water oxidation in this high value of applied potential.

Fig. 5 presents the UV spectra of the PCP standard (curve 1) and those obtained after the total time of electrolyses in the absence and presence of ultrasound (curves 3 and 4, respectively). Moreover, the UV spectrum obtained after the use of only ultrasound for the degradation of the compound is also shown in this figure (curve 2). It is known that radiation applied to aqueous solutions generates hydroxyl radicals by water sonolysis [15].

In a next step, decay curves of the normalized concentration ([PCP $\left.]_{t} /[\mathrm{PCP}]_{0}\right)$ of the pesticide as a function of degradation time in the absence and presence of ultrasound considering all spectrum bands were constructed. The curves representing the decay for band III spectrum are included in the inset of Fig. 5, for instance.

According to the spectra and the curves shown in Fig. 5, different levels of decay of each band of the spectrum of PCP after application of the procedures of degradation were obtained, as shown in Table 1. 


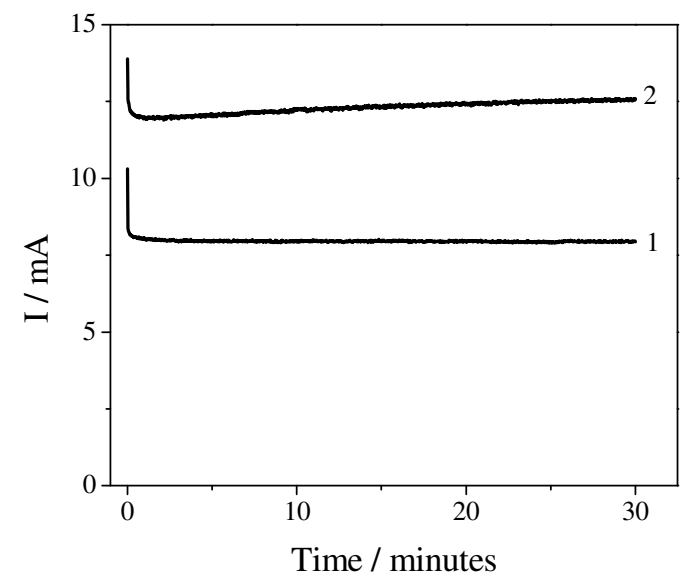

Figure 4. Electrolysis of the $\mathrm{PCP}$ at $3.0 \mathrm{~V} v s . \mathrm{Ag} / \mathrm{AgCl}$ in the absence (1) and presence (2) of ultrasound for a time of 30 minutes. Conditions: $[\mathrm{PCP}]=5.0 \times 10^{-5} \mathrm{~mol} \mathrm{~L}^{-1}$ in BR buffer $0.1 \mathrm{~mol} \mathrm{~L}^{-1}$ at $\mathrm{pH} 5.5$; ultrasound tip-BDD electrode distance $(\mathrm{d})=7 \mathrm{~mm}$ and intensity of ultrasound power (tip vibration amplitude, A) $=20 \%$.

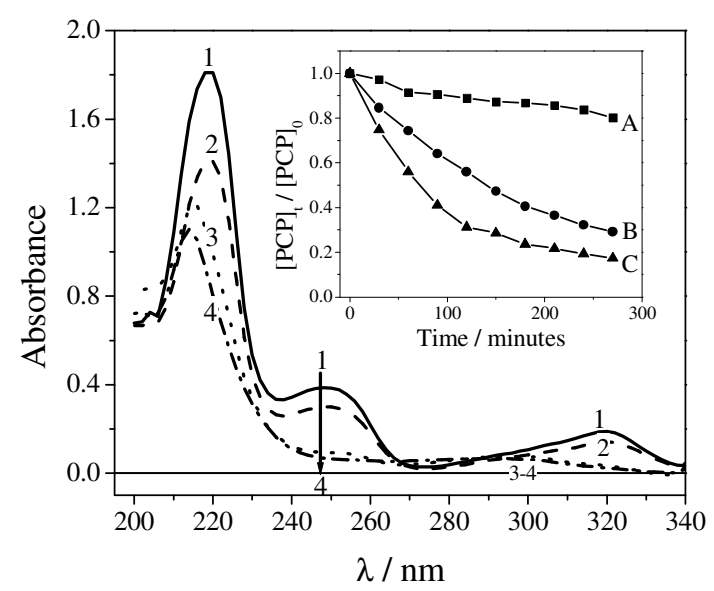

Figure 5. UV spectra for the PCP standard without degradation (1), after application of ultrasound without electrochemical process (2), after silent electrolyses (3) and sonoelectrolyses (4) both at $3.0 \mathrm{~V} v s$. $\mathrm{Ag} / \mathrm{AgCl}$. Inset: Decay curves, considering band III at $321 \mathrm{~nm}$, of the normalized concentration $\left([\mathrm{PCP}]_{\mathrm{t}}\right.$ at different times / $[\mathrm{PCP}]_{0}$ initial concentration $5.0 \times 10^{-5} \mathrm{~mol} \mathrm{~L} \mathrm{~L}^{-1}$ ) for application of only ultrasound (A), silent electrolyses (B) and sonoelectrolyses (C) as a function of degradation time. Conditions: BR buffer $0.1 \mathrm{~mol} \mathrm{~L}^{-1}$ at $\mathrm{pH} 5.5$; radiation conditions, when utilized: ultrasound tipBDD electrode distance $(\mathrm{d})=7 \mathrm{~mm}$ and intensity of ultrasound power (tip vibration amplitude, $\mathrm{A})=20 \%$.

The use of only ultrasound leaded to low significant levels of degradation of the PCP with a diminution of $\sim 20 \%$ of the initial concentration of PCP after $4.5 \mathrm{~h}$ of radiation application. This low performance is most likely due to the relatively small amount of hydroxyl radicals sonochemically generated at low ultrasound 
frequency applied $(20 \mathrm{kHz})$, since it was observed that the production of hydroxyl radicals is most significant at frequencies between 200 and $1000 \mathrm{kHz}$. Although cavitation is less violent at these high frequencies, there are more cavitational events and thus more opportunities for free radicals to be produced $[5,26]$. Thus, the highest levels of decay of the bands in the case of the sonoelectrolyses as compared to silent electrolyses are justified by the increase of mass transport, the minimization of inactivation electrode effects and the simultaneous generation of hydroxyl radicals by both ultrasound radiation and the polarized BDD surface [12, 27-31].

Table 1. Percentages of degradation of the PCP obtained by the different levels of decay for the PCP spectrum bands after application of only ultrasound and electrolyses at $3.0 \mathrm{~V}$ vs. $\mathrm{Ag} / \mathrm{AgCl}$.

\begin{tabular}{cccc}
\hline Procedures & \multicolumn{3}{c}{ Degradation percentages } \\
& Band I & Band II & Band III \\
\hline Ultrasound & 18.1 & 17.7 & 19.8 \\
Silent electrolyses $^{\mathrm{A}}$ & 29.3 & 71.6 & 70.8 \\
Sonoelectrolyses $^{\mathrm{B}}$ & 39.2 & 80.0 & 82.6 \\
\hline${ }^{\mathrm{A}} \mathrm{Q}=128.5$ C $^{\text {and }}{ }^{\mathrm{B}} \mathrm{Q}=190.4 \mathrm{C}$ & & &
\end{tabular}

In this context, the violent collapse of the bubbles produced in the electrolyte during ultrasound application can produce shock waves that contribute to mass transport [7, 32-35]. If the bubble collapses near the electrode surface, this will generate a jet that improves the transport of fluid. It is worth noticing that the acoustic flows are largely responsible for the convective flow to the solid-liquid interface [34]. Sonoeletrochemical experiments in which the ultrasound probe is placed in front of the electrode showed that it behaves as a hydrodynamic electrode. In such cases, the processes of diffusion and convection occur simultaneously contributing to the transport of electroactive material to the electrode surface [32].

Despite the interesting decay levels of the pesticide obtained by electrolyses, the results showed that there was a smaller decrease in band I of the UV spectrum of the PCP, for both applied procedures of electrolyses. It is suspected that aliphatic or cyclic organic species remained in the reaction medium after the procedures, since band I spectrum represents species ethylene ( $\mathrm{RCH}=\mathrm{CHR})$.

Considering the ability of ultrasound in cleaning and/or activation of the BDD surface, experiments using pulsed sonoelectrolysis $(\mathrm{Q}=180.8 \mathrm{C})$ were performed and the results are presented in Fig. 6. The consecutive increase and decrease of the mass transport in measurements in the presence and absence of ultrasound, respectively, were observed by the current values involved in the process. The inset of Fig. 6 shows the spectra obtained for the PCP standard and after the application of pulsed sonoelectrolysis. This experiment generated different decay levels of the PCP spectrum bands: $31.0,75.1$ and $76.3 \%$ for bands I, II and III, respectively. These values were intermediate as compared to values obtained by silent electrolyses and sonoelectrolyses (see Table 1). 


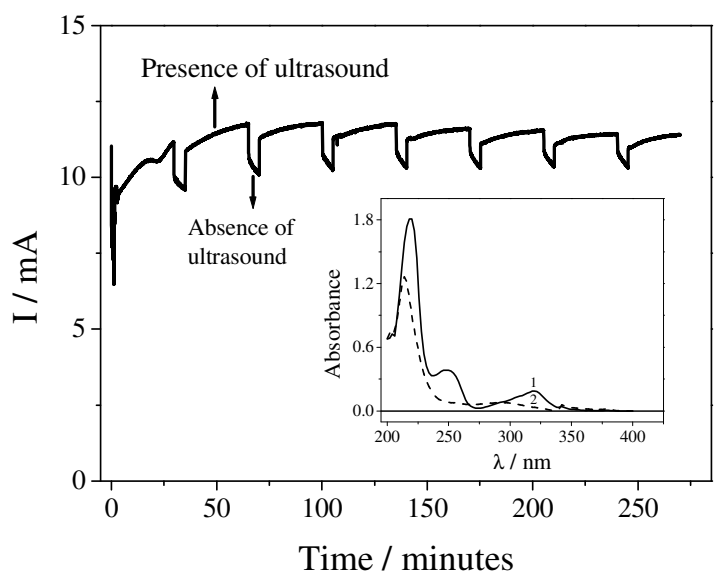

Figure 6. Pulsed sonoelectrolysis of the $\mathrm{PCP}$ at $3.0 \mathrm{~V} v s$. $\mathrm{Ag} / \mathrm{AgCl}$ for 270 minutes. Inset: UV spectra obtained for the PCP standard (1) and after the pulsed sonoelectrolysis (2). Conditions: [PCP]: $5.0 \times 10^{-5} \mathrm{~mol} \mathrm{~L}^{-1}$ in BR buffer $0.1 \mathrm{~mol} \mathrm{~L}^{-1}$ at $\mathrm{pH} 5.5$; ultrasound tip-BDD electrode distance $(\mathrm{d})=7 \mathrm{~mm}$ and intensity of ultrasound power (tip vibration amplitude, A) $=20 \%$.

The decay levels of the PCP bands obtained by pulsed sonoelectrolysis indicate that cleaning and/or reactivation of the electrode are really unnecessary for the degradation process, since electrode surface blocking was minimized by the use of ultrasound. Furthermore, the pulsed sonoelectrolysis prevents excessive heating of the solution, avoiding the use of cooling systems for practical applications. These features are very important and open the opportunity for future automation of pulsed sonoelectrochemical degradation of organic compounds for wastewater remediation.

However, similar to that observed in electrolyses in the absence and presence of ultrasound, aliphatic or cyclic species still remained in the aqueous media after the application of pulsed sonoelectrolysis, because band I of the spectrum showed a significant intensity. Therefore, the characterization of the final products of electrolyses of the PCP in the absence and presence of ultrasound, as well as the electrochemical degradation of the pesticide using high frequency ultrasonic sources, should be further performed, since these sources produce a larger amount of hydroxyl radicals in aqueous media.

\section{Conclusions}

The effects of the electrode surface activation provided by ultrasound and simultaneous generation of hydroxyl radicals by both radiation and polarized BDD surface contributed to higher levels of degradation of the pesticide in comparison to the values obtained for the silent electrolyses. Specifically for the case of pulsed sonoelectrolysis, the absence of reactivation and/or cleaning of the electrode surface could allow future automation of the process for industrial applications for long periods of time. 


\section{Acknowledgements}

The authors thank CNPq (Proc.142930/2005-9 and 304018/2009-0) and Fapesp (Proc. 06/50692-2) of Brazil for the scholarships and financial support to this work.

\section{References}

1. J. Barek, J. Fischer, T. Navratil, K. Peckova, B. Yosypchuk, J. Zima, Electroanalysis 19 (2007) 2003-2014. 10.1002/elan.200703918

2. A.K. Wanekaya, W. Chen, A. Mulchandani, J. Environ. Monit. 10 (2008) 703-712. 10.1039/b806830p

3. C.A. Martinez-Huitle, E. Brillas, Appl. Catal. B 87 (2009) 105-145. 10.1016/j.apcatb.2008.09.017

4. C.A. Martinez-Huitle, S. Ferro, Chem. Soc. Rev. 35 (2006) 1324-1340. 10.1039/b517632h

5. G.S. Garbellini, G.R. Salazar-Banda, L.A. Avaca, Quim. Nova 31 (2008) 123-133. 10.1590/S0100-40422008000100024

6. C.E. Banks, R.G. Compton, Analyst 129 (2004) 678-683. 10.1039/b403356f

7. R.G. Compton, J.C. Eklund, F. Marken, Electroanalysis 9 (1997) 509-522. 10.1002/elan.1140090702

8. J. González-García, M.D. Esclapez, P. Bonete, Y.V. Hernández, L.G. Garretón, V. Sáez, Ultrasonics 50 (2010) 318-322. 10.1016/j.ultras.2009.09.022

9. A.J. Saterlay, J.S. Foord, R.G. Compton, Electroanalysis 13 (2001) 10651070. 10.1002/1521-4109(200109)13:13<1065::AID-ELAN1065>3.0.CO;2-5

10. G.S. Garbellini, G.R. Salazar-Banda, L.A. Avaca, J. Braz. Chem. Soc. 18 (2007) 1095-1099. 10.1590/S0103-50532007000600002.

11. G.S. Garbellini, G.R. Salazar-Banda, L.A. Avaca, Food Chem. 116 (2009) 1029-1035. 10.1016/j.foodchem.2009.03.068

12. K.B. Holt, C. Forryan, R.G. Compton, J.S. Foord, F. Marken, New J. Chem. 27 (2003) 698-703. 10.1039/b300994g

13. G.H. Zhao, J.X. Gao, S.H. Shen, M.C. Liu, D.M. Li, M.F. Wu, Y.Z. Lei, J. Hazard. Mater. 172 (2009) 1076-1081. 10.1016/j.jhazmat.2009.07.113

14. C.H. Goeting, J.S. Foord, F. Marken, R.G. Compton, Diamond Relat. Mater. 8 (1999) 824-829. 10.1016/S0925-9635(98)00278-7

15. V. Naddeo, V. Belgiorno, D. Kassinos, D. Mantzavinos, S. Meric, Ultrason. Sonochem. 17 (2010) 179-185. 10.1016/j.ultsonch.2009.04.003

16. http://www.epa.gov/pesticides/reregistration/REDs/pentachlorophenol_red. pdf, accessed 19 October 2010.

17. G.S. Cooper, S. Jones, Environ. Health Persp. 116 (2008) 1001-1008. 10.1289/ehp.11081

18. L. Codognoto, S.A.S. Machado, L.A. Avaca, J. Appl. Electrochem. 33 (2003) 951-957. 10.1023/A:1025820029412

19. L. Codognoto, S.A.S. Machado, L.A. Avaca, Diamond Relat. Mater. 11 (2002) 1670-1675. 10.1016/S0925-9635(02)00134-6

20. D.A. Skoog, F.J. Holler, T.A. Nieman, Principles of Instrumental Analysis, Saunders College Publishing, Orlando, 1998. 
21. G.R. Salazar-Banda, L.S. Andrade, P.A.P. Nascente, P.S. Pizani, R.C. Rocha-Filho, L.A. Avaca, Electrochim. Acta 51 (2006) 4612-4619. 10.1016/j.electacta.2005.12.039

22. G.R. Salazar-Banda, A.E. Carvalho, L.S. Andrade, R.C. Rocha-Filho, L.A. Avaca, J. Appl. Electrochem. 40 (2010) 1817-1827. 10.1007/s10800-010-0139-1

23. R.M. Silverstein, G.C. Bassler, T.C. Morrill, Identificação espectrométrica de compostos orgânicos, Editora Guanabara Dois S. A., Rio de Janeiro, 1979.

24. M. Quiroz, S. Reyna, J. Sanchez, J. Solid State Electrochem. 7 (2003) 277282. $10.1007 / \mathrm{s} 10008-002-0340-1$

25. B. Marselli, J. Garcia-Gomez, P.A. Michaud, M.A. Rodrigo, C. Comninellis, J. Electrochem. Soc. 150 (2003) D79-D83. 10.1149/1.1553790

26. A. Al Bsoul, J. Magnin, N. Commenges-Bernole, N. Gondrexon, J. Willison, C. Petrier, Ultrason. Sonochem. 17 (2010) 106-110. 10.1016/j.ultsonch.2009.04.005

27. M. Rivera, M. Pazos, M.A. Sanroman, J. Chem. Technol. Biotechnol. 84 (2009) 1118-1124. 10.1002/jctb.2141

28. X. Zhu, J. Ni, H. Li, Y. Jiang, X. Xing, A.G.L. Borthwick, Electrochim. Acta 55 (2010) 5569-5575. 10.1016/j.electacta.2010.04.072

29. R.H. de Lima Leite, P. Cognet, A.M. Wilhelm, H. Delmas, Chem. Eng. Sci. 57 (2002) 767-778. 10.1016/S0009-2509(01)00433-X

30. T.A. Enache, A.M. Chiorcea-Paquim, O. Fatibello-Filho, A.M. OliveiraBrett, Electrochem. Commun. 11 (2009) 1342-1345. 10.1016/j.elecom.2009.04.017

31. A. Kapalka, G. Foti, C. Comninellis, Electrochim. Acta 54 (2009) 20182023. 10.1016/j.electacta.2008.06.045

32. E.L. Cooper, L. Coury Jr., J. Electrochem. Soc. 145 (1998) 1994-1999. $10.1149 / 1.1838588$

33. K.B. Holt, J. Del Campo, J.S. Foord, R.G. Compton, F. Marken, J. Electroanal. Chem. 513 (2001) 94-99. 10.1016/S0022-0728(01)00600-3

34. R.G. Compton, J.C. Eklund, S.D. Page, T.J. Mason, D.J. Walton, J. Appl. Electrochem. 26 (1996) 775-784. 10.1007/BF00683739

35. C.E. Banks, R.G. Compton, ChemPhysChem 4 (2003) 169-178. 10.1002/cphc.200390027 